\title{
Corynebacterium pseudodiphtheriticum
}

National Cancer Institute

\section{Source}

National Cancer Institute. Corynebacterium pseudodiphtheriticum. NCI Thesaurus. Code C86320.

A species of aerobic or facultatively anaerobic, Gram-positive, coryneform, pleomorphic bacilli assigned to the phylum Actinobacteria. This species is nonmotile, non-spore forming, catalase positive, oxidase negative, pyrazinamidase positive, non-lipophilic, reduces nitrate, urease positive, does not ferment glucose, sucrose, or maltose, and is reverse CAMP positive. C. pseudodiphtheriticum is commensal in the nasopharynx and is known to cause lower respiratory infections and endocarditis. 